UNIVERSITY OF CHITRAL JOURNAL OF LINGUISTICS AND LITERATURE

\title{
Jokes are not Innocent: Representation of Punjabis in Pashto Jokes
}

\author{
Muhammad Waqar Ali \\ $\mathrm{PhD}$ scholar (Linguistics) and lecturer at the Department of English, Islamia College University \\ Peshawar
}

\begin{abstract}
In this paper, the researcher analysed racist or ethnic jokes as a genre of discourse to investigate the issue of representation of Punjabis in Pashto jokes. The emphasis of the paper was on understanding stereotypes and symbols associated with the representation of Punjabis in Pashto jokes. The data for the study comprised oral jokes of Pakhtuns from Peshawar. The researcher followed John stone (2008) and Linde (1993) for discourse analysis of the jokes. Further, the researcherfollowed Althusser (1971) as theoretical framework to explain the reason(s) behind the way Pakhtuns present Punjabis in their jokes. At the end, the researcher concluded that ideology through cultural Ideological State Apparatus interpellates (i.e. calls out or hails) Pakhtuns as subjects.
\end{abstract}

Key words: jokes, Punjabis, Althusser, Ideological state apparatuses, Pakhtuns

\section{Introduction}

Ethnicity is an agonizing yet undeniable reality of Pakistani society. Ethnicity in Pakistan is more likened to provincialism and linguistic ethnicity. Ethnic or racist discourse generally expresses ethnic attitudes of social, cultural or ethnic groups towards others. Since discourse is shaped by and shapes the world (Johnstone, 2008) and is in fact "a form of social practice, action, or interaction" (Van Dijk, n.d., p.115), its analysis can improve our understanding of the issue at hand. More, it can lead to the understanding of socio-cultural make-up of the Pakistani society. Daily observation of discourse on media and elsewhere can easily verify existence of racist and ethnic communicative practices. Racist discourse is not limited to media only; it is available in all political, social and cultural domains and multiple genres of discourse such as drama, comedy shows, conversation, movies, songs, cartoons, stand-up comedy, jokes and so forth.

As racist or ethnic discourse cannot be analyzed from every aspect in a paper like this short length, the researcher's focus in this study is on merely one genre of discourse: jokes. Furthermore, Pakistan comprises a multitude of ethnicity: both linguistic and racial, and it is not possible to discuss all of them in such a short discussion. Among this multitude of ethnic groups, Punjabis are the largest ethnic group comprising of $44.15 \%$ of the total population of the country and Pakhtuns are the second largest ethnic group making up for $15.42 \%$ of the total population (n.a., Population by mother tongue, 2017). Punjabi- Pakhtun tussle pervades every discursive event held in the two provinces namely, the Punjab and Khyber Pakhtunkhwa. Nowadays, it is a common issue that Punjabis, being politically, socially and culturally dominant, marginalize Pakhtuns in discourse 
(Gazdar, 2007; Kupecz, 2012; Bhattacharjee, 2015). The researcher actually wants to know how the marginalized Pakhtuns react and represent Punjabis in the discourse of Pakhtuns, particularly in their jokes - a genre of discourse. So, the researcher limits his discussion to the analysis of representation of Punjabis in Pashto jokes.

\section{Literature Review}

Among various popular definitions of Humour, the following two are more significant. Crawford (1994) defines humour as any communication that generates a "positive cognitive or affective response from listeners" (p. 57).Similarly, Romero and Cruthirds (2006) define humour as "amusing communications that produce positive emotions and cognitions in the individual, group, or organization" (p. 59). Both definitions accentuate evocation of positive emotions or response. However, racial humor gives vent to ethnic emotion. Freud (1960), in this regard, articulates that people use humor to manifest their repressed antagonistic instinctive urges in a socially tolerable way.

Many have suggested racist humour is of the Hobbesian kind, a laugh at sudden glory, a form of ridicule, or some other derivative of the superiority theory (Weaver, 2010).The superiority theory of humour states that what makes us laugh is the sudden glory of realizing the misfortunes or disagreeable attributes of others, which make ourselves seem superior to them even though we are well aware of our own defects. Superiority humour pokes fun at certain people by pointing out their perceived weaknesses, misfortunes, or defects.

Apart from poking fun at other people, the superiority jokes often poke at people who are members of certain social classes, or social groups. The superiority theory says that humour is a manifestation of a feeling of superiority over others or even over one's own former situation (Berger 1987; Cooper 2008). In other words, a humorous utterance can be a sign of the person "lording" (Sen2012:2) it over another person whom he or she considers inferior. In the case of self-deprecating humour, it can be the case that the person is making the humorous comment to distract others' attention away from a gaffe that he or she has committed.

\section{Methodology}

Since qualitative investigation requires thorough analysis of data, it become difficult to manage enormous data in a paper-length study. For instance, Weaver (2011) analyzed anti-black jokes of 5 websites. Similarly, Burdsay (2011) limited his data for the analysis of jokes to the interviews of a couple of Asian players. The data for this paper comprise some Pashto jokes, five in number. The researcher has collected these jokes from Pashto speakers who are the residents of Khyber Pakhtunkhwa, and all of them are educated. Some of these jokes have been received in text form and some have been shared verbally. It is worth mentioning that there was a chance of misinformation by the respondents. They could just change the names of the characters in the joke which are actually quoted to represent other social or cultural groups, and could send me such jokes that do not represent Punjabis. To avoid such an apprehension, the researcher clearly 
communicated and required the respondents to narrate typical jokes wherein they (Pakhtuns) express their feelings about Punjabis.

So far as analysis of the data (jokes) is concerned, the researcher agrees with Sen (2012) who believes that jokes are analyzed through the analysis of the words. The researcher follows Johnstone (2008), Linde (1993) for discourse analysis, and Barthes (1988) for semiotic analysis of cultural symbols used in jokes to represent the 'other' (Punjabis). Further, the researcher follows Penelope (1990) to check presence or absence of agency. At the end, my conclusion develops on Althusser's (1971) "Ideology and Ideological State Apparatuses".

The jokes are narrated and texted in Pashto. In this paper, the researcher is writing their English translation.

\section{Discussion}

Said (1978) has discussed the notion of representation in detail in his seminal work, Orientalism. He establishes the importance of discourse in constructing and/or representing social reality. A very common instance of such phenomenon is representation of the Orient by the Occident. The Orient is defined in terms of stereotypes. Likewise, social or ethnic groups represent the 'others' in form of stereotypes. Later on, these stereotypes along with certain beliefs and notions become a part of "social wisdom" (Siddiqui, 2013, p.86).

Jokes are a significant and powerful tool of representing the 'other' and constructing the stereotypes that define the 'other'. Pakhtuns represent Punjabis (the other) through different stereotypes and have attached different symbols to the represented identity of Punjabis. For instance, in the following joke, Punjabis are represented as dupes and fools.

Joke 1:

001: A Punjabi went for pilgrimage

02 : When he returned,

003: his friend asked him

004: You stoned Satan there?

005: (Punjabi), I could not get a chance to stone

006: but I called [him] names a lot.

This joke has two structural components: setting and punch line. The setting extends from L. 001 to L. 004. The setting of the joke sets a scene or describes a situation, and the punch line LL. 005006 represent Punjabis as fools and dull people. As per common sense, a pilgrim is supposed to stone Satan rather than to abuse him. More, pilgrimage (Haj) is a very sacred ritual which necessitates pilgrim's complete knowledge about it. So, Punjabis are represented here as nonseries people in the religious affairs and ignorant of religious knowledge. Moreover, the use of the expression in L.006 indicates that the Punjabi considered calling names an adequate replacement of stoning. This makes the Punjabi a laughing stock for Pakhtuns.

Additionally, the joke is narrated in indirect (LL.001-004) as well as in direct narration (LL.005006). The use of direct narration for the punch line (LL.005-006) indicates that joke-tellers 
want to retain authenticity of the foolery exhibited in the joke. Had it been stated in indirect way, it would have enfeebled the force of the punch line as a proof of dullness of Punjabis on the pretext that the words (uttered indirectly) might have been altered.

Agency has been established for the Punjabi in L.006 since he says 'the researcher called him names a lot.'The explicit agency for the Punjabi in this example implies that he takes responsibility of his action. Penelope (1990) articulates that human agency is "suppressed to evade responsibility for some action" (p.144).

Joke 2:

007: A Punjabi printed a fake bill (of Pakistani currency)

008: but forgot printing (Jinnah) cap (on Quaid-e-Azam's head)

009: (shopkeeper), there is no cap on his head.

010: (Punjabi), it is his picture in summer

Joke 2 also follows the structural norm of two parts: setting, and punch line. A stereotype of fraud is ascribed to Punjabis in L. 007 as the Punjabi in this joke produces fake currency bills. Pakhtuns consider Punjabis fraudulent people who would commit crimes. They are presented as cunning, fraudulent and sham people. However, the stereotype of dullness is existent in this joke as well. As per LL.008-009, he forgets to print the cap. It shows his carelessness. This stereotype is extended to all Punjabis by Pakhtuns. In the punch line (L. 010), which creates fun, he comes up with a more imprudent and irrationalreply that the picture was shot in summer which is unacceptable even to a child.

Joke 3:

011: A Pakhtun was dining in a hotel

012: having eaten meat, he was chewing a bone.

013: A Punjabi, sitting next to him, asked him (the Pakhtun) 014: Khan sab, what do dogs eat in your area?

015: the Pakhtun replied 'lentil'.

Joke 3 is a symbolically rich joke. Along with symbols, it carries some presuppositions as well.

The first symbol used here is 'meat'. In Pakhtun culture, meat is associated with Pakhtun cuisine while 'lentil' is attached to Punjabi cuisine. Both symbols have opposite cultural connotations. Culturally, meat is considered a rich source of energy; therefore it is associated with Pakhtuns to manifest that they are strong and healthy. Conversely, the cultural assumption that lent is less nutritious islinked with Punjabi cuisine to represent them physically feeble, weak and unhealthy.

Besides the two referred symbols, worth discussing symbol is 'bone'. Apart from its literal meaning, bone stands for worthless, valueless and insignificant things. More, a presupposition is attached with this symbol that only dogs chew bone. When the Punjabi (L. 014) seeing the Pakhtun who was chewing a bone asks what dogs eat in the latter's area (e.g. city or province), he wants to implicitly refers the Pakhtuns as dogs because it is presupposed that bones are chewed by dogs. 
However, he does not succeed and is tricked in his own trap when the Pakhtun answers him that dogs in their place eat 'lentil'. So, he calls the Punjabi a dog because the symbol 'lentil' is associated with Punjabis. Again, the Punjabi is represented as less intelligent than the Pakhtun. Another feature of the joke is the use of abusive language. Abusive language is a very common aspect of racist humour.the researcher has come across many jokes carrying abusive words to represent Punjabis.

Joke 4:

016: (a Punjabi to a doctor), how much does plastic surgery cost?

017: (the doctor), 2 lac.

018: (the Punjabi), and if we bring plastic with us.

Though a brief one, Joke 4 is replete with witty humour. It speaks of lack of wisdom and common sense in Punjabis' cognitive faculty. In this joke, Punjabis are represented as a cognitively weak ethnic group. In the discourse, they are presented as incompetent users of language in general and that of discourse in particular. The Punjabi interprets the word 'plastic' in L.016 in its literal meaning. He does not comprehend the domain-specific meaning of 'plastic surgery'. He cannot differentiate between use of the word 'plastic' in medical science and its use in routine life.

Joke 5:

019: A Punjabi's wife was very belligerent.

020: once his wife started reprimanding him due to something

021: for a while, he kept on smiling

022: then he left the room

023: and sat outside

024: when his wife realized that

025: it was not affecting him

026: consequently, she poured a pail full of water on him

027: the Punjabi, being wet, started laughing

028: and said

029: I knew

030: it would happen

031: after thunder, it always rains.

The jokes discussed so far deal with the public life of Punjabis and represent them in their public domain. The joke 5 is an illustrated example of their representation in domestic or private life.

The line (...) of this joke connotes that it is the female who dominates the domestic world in a Punjabi family. In Pakhtun discourse about Punjabis, presence of a bellicose wife in a family (if the family is still intact) presupposes presence of a servile and submissive husband in Punjabi culture.

The Punjabis are stereotyped as unconscientious and devoid of grace or self-esteem. His wife upbraids him, and he keeps on smiling. Worse than this, when it does not satisfy her, she pours 
water on his head (L.21) and he still smiles. Instead of getting irritated, he remains calm and cool. In the Pakhtun discourse, this sort of compromise, calm and normalcy on part of a husband is interpreted as cowardice, servility and submissiveness. And such a person is not acceptable in Pakhtun society. Consequently, Punjabis, in their domestic life, are represented as very obedient and docile husbands who are dominated by wives. Such situation carries very shameful and negative connotation in the Pakhtun culture. Rather, it is the worst thing in a Pakhtun's life to be ruled or guided by a woman.

This joke tarnishes the ethnic and social stature or image of Punjabis. They, as an ethnic group, have been represented as racially, physically and socially weak people who are not at par with Pakhtuns and cannot match them.

Generalizing all jokes, it is apparent that there are some similarities among all five jokes. First, all jokes consist more or less of two parts: setting, and a punch line. Setting provides a background or a situation for the punch line of the joke. It is a larger part of a joke. On the other hand, a punch line a brief line that comparatively is shorter than the setting of the joke. The punch line is essence of the joke. It is a moment of humour in narration of jokes. Second, 'intertextuality' can also be observed in the jokes. Kristeva coined the term for the "ways in which texts... built on other texts and discourses" (as cited in Johnston, 2008:164).There are some words and expressions (at times situations) which are prevalent in many of the aforementioned joked. Recursion of stereotypes and symbols also affirms intertextuality in jokes.Third, all the jokes have same narrative style. Every joke begins with indirect narration and end with direct narration. Most of the punch lines are in direct narration and active voice. This is done intentionally to maximise element of humour in jokes.

\section{Conclusion}

Johnstone (2008) has discussed that culture creates, shapes and is created and shaped by discourse. Discourse does not mean an amalgam of meaning and context. Instead, Van Dijk (n.d.) suggests that "each text or talk is monitored by underlying... social cognitions (knowledge, attitudes and ideologies)" (p.99). Similarly, there is some social cognition(s) (Freud, 1960) underlying these jokes. Every social, ethnic, cultural or religious group is under the influence of some ideology-a set of ideas and/or beliefs. And the best location of ideology is language, in general, and discourse, in particular. Fairclough (1995) suggests the same, "ideology invests language in various ways at various levels, and that we don't have to choose between different possible 'locations' of ideology, all of which seem partly justified and none of which seems entirely satisfactory" (p. 71). Since ideology is invested in language or discourse at various levels, the researcher opted for jokes to investigate ideology in the Pakhtun culture. The researcher here attempts to answer the question: Why do Pakhtuns represent Punjabis in the aforesaid manner? What are the reasons that cause such behavior?

It has rightly been stated that "man is an ideological animal"(Althusser, 1971, p. 171). No culture or society does exist without ideology. To Althusser ideology is ahistorical. It does not have any 
past, present or future. The representation of Punjabis in Pashto jokes is actually the result of ideology underlying discourse (language). Since ideology promises identity (Althusser, 1971), Pakhtuns establish identity for themselves as well as for Punjabis in Pashto jokes. It is a kind of binary opposition between Pakhtuns and Punjabis: 'we' and 'they' (the others) respectively. The representation of the 'otherness' in Pashto racist jokes leads to the formation of group (social) identity among Pakhtuns. Generally, racist jokes are shared and narrated in conversation or discussion occurring among the members of the same group. Likewise, Pakhtuns share ethnic jokes among their group fellows. Therefore, some of the respondents were reluctant to share racist jokes with me unless the researcher ensured them that these jokes would be used for research.

Another aspect the analysis can be explained through the Althusserian concept of interpellation. Althusser believes (1971) that ideology interpellates individuals and converts them into subjects.

Fairclough writes in this regard, "ideology has material effects, and discourse contributes to the creation and constant re-creation of the relations, subjects (as recognized in the Althusserian concept of interpellation) and objects which populate the social world" (1995:73).

Althusser (1971:173) states about interpellation:

all ideology hails or interpellates concrete individuals as concrete subjects...ideology 'acts' or 'functions' is such a way that it 'recruits' subjects among the individuals... or 'transforms' the individuals into subjects ... by that very precise operation which the researchers have called interpellation [italics original]or hailing.(1971, p. 173-74)

Pakhtuns are interpellated or hailed by ideology, and they are being converted into good (universal)subjects. Ideology is at work through discourse (i.e. jokes). The more they share such jokes, the more they are interpellated by ideology as subjects. Related to this, there is one more Althusserian concept, namely, Ideological State Apparatuses (ISAs) that needs discussion. Defining ISAs, Althusser (1971) states"I shall call Ideological State Apparatuses a certain number of realities which present themselves to the immediate observer in the form of distinct and specialised institutions" ( p. 143).Althusser (1971) opines that Ideological State Apparatuses (ISAs) are a part of the private domain and function by ideology. In this regard, Althusser writes: (Repressive)State Apparatus belongs entirely to the public [italics original] domain, much the larger part of the Ideological State Apparatuses (in their apparent dispersion) are part, on the contrary, if the private [italics original] domain.... Private institutions can perfectly well 'function' as Ideological State Apparatuses.... What distinguishes the ISAs from the (Repressive) State Apparatus is the following basic difference: the Repressive State Apparatus functions 'by violence', whereas the Ideological State Apparatuses function 'by ideology' [italics original].(1971: 144-45)

The researcher believes that the ISA through which ideology is functioning, is culture. The ISA of culture can vividly be observed in the Pakhtun discourse about Punjabis. The cultural belief of lack of religiosity in Punjabis pervaded many jokes. Along with it, the notion that Punjabis are dull, dupes and fools is also highlighted in these jokes. 
It has been opined earlier that ideology promises identity (individual as well as social); more, ideology works through ISAs using discourse. And it has also been established that discourse creates culture as well as social reality. So the same discourse can further lead to action since ideology, according to Fairclough (1995) creates and re-creates relations. Therefore, jokes are not innocent and they can cause rift between the two ethnic groups, namely, Pakhtuns and Punjabis; and with the passage of time it might be widened. Many have suggested the same thing opining that racist humour can cause offence or psychological damage, and that it could affect group morale (Fry, 1977; La Fave, 1977 as cited in Weaver, 2010). This study is an attempt to raise consciousness about the emergent racial differences and ethnic divide that is widening the gap between the two ethno-cultural sections of Pakistani society: Pakhtuns and Punjabis. If we do not realize the damage these "innocent jokes" can do and are doing, the chasm will outgrow our capacity to refill and repair it. Realizations of the problem is the first step to make amends for the same, and this study was an attempt to take that first step. However, the study is not an all-inclusive and comprehensive in its effort to make generalizations because the data was limited to only five jokes. One reason for the limited data was that the respondents were not willing to share jokes for the purpose of documentation and research. Since it is a potential area of research with little research available, other studies could be administered analyzing a large amount of data to make more credible generalizations and also to ascertain the intergenerational differences ofPakhtuns' attitude towards Punjabis in the former's jokes and vice versa in the latter's.

\section{References}

Althusser, L. (1971). Lenin and philosophy and other essays. New York: Monthly Review Press. Berger, A. (1987). Humour: An introduction. American Behavioural Sceintist, 30 (1), 6-16.

Bhattacharjee, D. (2015). The Missing Persons of Balochistan in Pakistan. Retrieved from SSRN: https://ssrn.com/abstract=2612286

Burdsey, D. (2011). That joke isn't funny anymore: Racial microaggressions, color-blind ideology and the mitigation of racism in English men's first-class cricket. Sociology of Sport Journal , 28 (3), 261-283.

Cooper, C. (2008). Elucidating the bonds of workplace humour: A relational process model.

Human Relations (61), 1087-1115.

Crawford, C. (1994). Theories and implications regarding the utilization of strategic humour by leaders. The Journal of Leadership Studies (1 (4)), 53-67.

Fairclough, N. (1995). Critical discourse analysis: The critical study of language. London and New York: Longman.

Freud, S. (1960). Jokes and their relation to the unconscious. New York: W W Norton.

Gazdar, H. (. (2007). Class, caste or race: veils over social oppression in Pakistan. Economic and Political Weekly, 86-88.

Johnstone, B. (2008). Discourse Analysis (2nd ed.). New York: Blackwell.

Kupecz, M. (2012). Pakistan's Baloch insurgency: History, conflict drivers, and regional implications. International Affairs Review , XX (3), 95-110.

Linde, C. (1993). What is a life story? Life Stories: The creation of coherence. New York City : 
Oxford University Press.

n.a. (2014, April 12). Ethnicity in Pakistan. Retrieved May 09, 2015, from Ethnicity in Pakistan: http://ethnicityinpakistan.blogspot.com/About\%20Us

n.a. (2017). Population by mother tongue. Retrieved November 18, 2018, from Bureau of statistics: Government of Pakistan: http://www.pbs.gov.pk/content/populationmothertongue

Penelope, J. (1990). The agents within. In J. Penelope, Speeking freely: Undoing the lies offather's tongue. New York City: Teachers College Press.

Romeo, E. \&. (2006). The Use of Humour in the workplace. Academy of Management Perspective (20 (2)), 58-69.

Sen, A. (2012). Humour analysis and qualitative research. (N. Gilbert, Ed.) Social Research Update (63), 1-4.

Siddiqui, S. (2013). Language, Gender, and Power: The politics of representation and hegemony in South Asia. Karachi: Oxford University Press.

Van Dijk, T. A. (n.d.). Analysing racism through discourse analysis: Some methodological reflections. in print.

Weaver, S. (2010, November 20). Developing a rhetorical analysis of racist humour: examining anti-black jokes on the internet. (20:5), 537-555. London: Routledge.

Weaver, S. (2011). Jokes, rhetoric and embodied racism: A rhetorical discourse analysis of the logics of racist jokes on the Internet. Ethnicities , 11 (4), 413-435. Literature, Pakistan. This article is an open access article distributed under the terms and conditions of the Creative Commons Attribution (CC BY) (http://creativecommons.org/licenses/by/4.0/). 